\title{
Creation of an ISO Standard at the example of Value Stream Management method
}

\author{
Jeff Mangers $^{1}$, Christof Oberhausen ${ }^{2}$, Meysam Minoufekr ${ }^{1}$, Peter Plapper ${ }^{1}$
}

${ }^{1}$ University of Luxembourg, Luxembourg

${ }^{2}$ Paul Wurth Geprolux S.A., Luxembourg

\begin{abstract}
In a globalized economy, standards need to be generally accepted and valid for all countries. Thus, corporate or national standards, only have limited impact. The International Standardization Organization (ISO) provides the means to develop, negotiate and finally communicate standards, which are globally binding.

This chapter shares the experience how to author an ISO norm based on the example of Value Stream Management (VSM), ISO 22468. It covers the organization of ISO, explains Technical Committees and Working Groups, their mode of operation to obtain approval from the national norming authorities of ISO and explains the different phases of ISO standard development.

These generic steps have been applied to the norming process of VSM, which is led by TC $154 \mathrm{WG} 4$. The standardized VSM method now enables to capture manufacturing data, to analyze value steams and to design optimal value creation processes in a common fashion.

Value Stream Management (VSM) is a standardized method for the analysis, design and planning of value streams, which is led by ISO/TC 154 WG 7. This is substantial, since most companies operate in businessto-business (b-2-b) environments and need a suitable method for reliable, efficient and flexible collaborations in agile supply chain networks (SCNs). With increased exploitation of Information and Communications Technology (ICT), diverse VSM approaches are currently used, which limits the crossenterprise applicability. Thus, a common VSM standard enables to capture data and to synchronize product flows and identify opportunities to reduce waste.
\end{abstract}

Keywords: Operational Excellence; Lean; Stages; Supply Chain Networks; Cross-Enterprise; Businessto-Business; Patents; Software

\section{INTRODUCTION}

Standards are currently taking a more and more important role in our daily life. They help to provide consumers with confidence that their products and services are safe, reliable and of appropriate quality. The organization ISO (International Organization for Standardization) is an independent, non-governmental international organization, which associates experts from all over the world. Thus, it is possible to combine and share the global knowledge to develop international standards that support innovation and provide solutions for global challenges [ISO 2019-1].

The idea of standardization started with obvious things like measures and weights. Nowadays, standards can be found in nearly every component or part of our daily life. Standards on road safety, toy safety, workplace safety, transportation safety, credit cards, paper sizes, currencies and secure medical packaging 
are just a few relevant standards that help make the world a safer place. Regulators and governances count on standards to help develop better regulations, by knowing that globally-established experts have created the sound basis [ISO 2019-1]. To ensure this significant quality, the work of preparing international standards is carried out through ISO technical committees, which is a group of experts [ISO 2019-2]. To ensure an equivalent quality understanding, standards like ISO-9001 are used, and to provide a common understanding and execution of methods, standards like the currently developed ISO-22468 can be used.

Here we want to use the example of Value Stream Management to explain how to set up an international standard, which is the highest level of standard in view of effort quality, and also impact.

The VSM was made popular by Rother and Shook [Rother \& Shook, 1999] and was used for many years by different authors to assess manufacturing operations and to distinguish waste from value adding processes, in order to minimize waste and shorten lead time [Plapper, 2011, ... weitere Lit.]. However, over the years a large variety of VSM methods has evolved, tailored to the alleged slightly different use cases of every operation. Most companies operate in b-2-b supply chain networks, which spreads the value creation across many firms. Often VSM is applied within the plant or inside the company. However, the application of this tool across company borders is restricted due to different corporate standards. This limits to create a value stream map across the entire SCN. Still, this distributed value creation network is standard in most industries, but not addressable with today's tools.

For example, the large, globally dominating original equipment manufacturers (OEMs) of aviation industry developed their own corporate VSM rules, which they impose to their suppliers. This means that the Tier 1 or even Tier 2 suppliers need to follow the corporate rules to pass and audit. They need to describe their own manufacturing processes according to the corporate standard of the OEM which is partially contradictory to the corporate standard of the other OEMs. This compliance requirement drives waste of rework, especially reformatting of the documentation by the supplier, which drives multiple loops of VSM documentation without adding value to the process or final product [Oberhausen, Minoufekr, Plapper, 2017-1].

Another example, where a common method is needed is cross enterprise VSM. This can only be analyzed with one common method. This common VSM method is a major pre-requisite to optimize the entire SCN, because the norm also enhances b-2-b information transparency.

A common standard, which would be internationally accepted would eliminate this type of multiple documentation of the VSM. The norm development process described in this paper uses the VSM standard 22468 as example for an ISO norming process.

The remaining of this publication is structured as follows: First, the current challenges of SCNs are analyzed in detail, followed by existing VSM methods, patents and commercial software. The third chapter describes the work of ISO Technical Committee (TC), and the individual steps from the draft to the final ISO norm. An administrative use case of the VSM standard proves the applicability of this method and documents its advantages.

\section{BACKGROUND}

\section{CHALLENGES-OF VALUE STREAM MAPPING AND DERIVED SCIENTIFIC QUESTION}

Communication issues lead to misunderstandings, which sometimes create collaboration challenges between departments and even more between enterprises. They result from ambiguous information, 
insufficient transparency or conflicting targets related to the value creation process. Furthermore, changes enforced by increasingly demanding customers may require modification of materials, components or associated processes. Fehler! Verweisquelle konnte nicht gefunden werden. visualizes the information flow of b-2-b orders and the product flow towards the end customer, with obstacles at the interfaces between the companies that inhibit an effective supply chain cooperation.

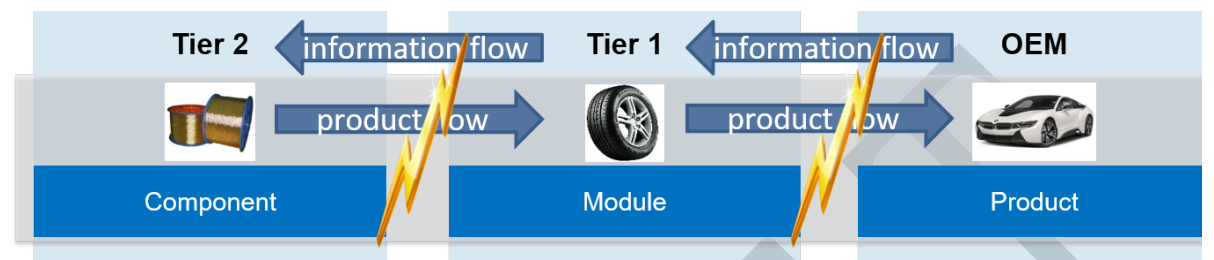

Figure 1. Example of a cross-enterprise supply chain (Sources of pictures, 2017)

Especially in case of internal or supply chain audits, when the overall process flow needs to be mapped, analyzed and discussed beyond departmental or organizational boundaries, complications and misunderstandings arise i.e. from notational differences that result in rework and finally in a waste of resources. To overcome the communication and collaboration difficulties in supply chain networks, tools and techniques originating from Lean Production are transferred to further industrial sectors [Oberhausen \& Plapper, 2015]. VSM is an established technique to analyze and to design value streams within organizations [Plapper \& André, 2011]. However, due to a heterogeneous landscape of VSM approaches, there is no common understanding of value stream data, especially across company or corporate borders.

The information transparency further decreases while considering different types of VSM patents and applying a variety of VSM software solutions. Thus, this diversity in regard to the use of VSM creates a need for standardization. Based on a comparison of existing VSM approaches, a standardization of VSM in four different categories is proposed (cf. [Oberhausen \& Plapper, 2015]):

- VSM symbols,

- VSM data boxes and VSM parameters,

- Value stream calculation, and

- Value stream visualization.

In this context, the following assumption can be formulated:

A standardized VSM method will facilitate the communication and collaboration in complex supply chain networks, based on a common understanding and accessibility of value stream data.

To verify this key assumption, following two research questions need to be investigated in that respect:

1) How to develop an ISO standard from the idea to the published version?

2) How to define a generic VSM standard that is suited for its uniform application across different industry sectors?

\section{STATE OF THE ART}

To resolve supply chain issues as stated by [Wang, Heng, \& Chau, 2007], a standardized cross-enterprise VSM method is sought [Oberhausen \& Plapper, 2016]. According to previous publications about the standardization of methods and processes, the process complexity and sectoral differences need to be taken into account [Schäfermeyer \& Rosenkranz, 2011] [Schmitz \& Leukel, 2005]. In line with the claim for cloud technology, where "standardization for interoperability" is required, as stated by [Gao, 2015], a 
common VSM methodology in consideration of existing VSM approaches, patents and software solutions will enhance the collaboration and communication in interconnected value networks.

In the following, the state of the art of the currently used VSM approaches, the patents in the field of VSM and VSM software will be discussed briefly. Further details can be retrieved from [Oberhausen, Minoufekr, Plapper, 2017-1].

A) VSM approaches

Numerous different VSM approaches [Hines, 1999], [Rother\& Shook, 1999], [Keyte \& Locher, 2004], [Klevers, 2007], [Erlach \& Brown, 2013], [Badurdeen \& Amundson, 2014] exist and moreover, [Womack \& Jones, 2011] developed a VSM extension for supply chains. To handle this variety of different approaches, a detailed comparison of existing VSM methodologies has been performed to enable a generic and accurate use of VSM.

B) Patents in the field of VSM

To gain a comprehensive overview of existing VSM concepts and solutions and for the subsequent definition of a standardized VSM method, a patent review has been conducted, which can be found in Appendix 1, Table 1. As part of the ISO standard development, it needs to be clarified which of these patents are competing or complementary. In case of competing patents, fair, reasonable, and nondiscriminatory terms (FRAND) are suitable to support a mutually beneficial cooperation.

\section{C) VSM Software}

Numerous IT solutions are available on the market for the analysis, simulation and design of value streams. These software solutions can be classified in three different categories, VSM Templates or Add-Ons, VSM Drawing Applications and VSM Stand-Alone Simulation Software [Oberhausen 2018].

[Oberhausen 2018] includes an exhaustive list of literature about VSM. It is structured in 4 groups:

- Conventional VSM methods and literature studies,

- VSM with reference to industrial engineering, and key performance indicators (KPI)

- Further refinement and extendend applications of VSM

- Transfer of VSM to b-2-b interactions and SCN

The existing VSM approaches, patents and software reveals an inconsistent conception that leads to a divergent understanding of VSM. This is particularly problematic for the collaboration and communication of organizations within cross-enterprise SCN [Oberhausen, Minoufekr, Plapper, 2017-1].

\section{VSM STANDARD DEVELOPMENT}

The state of the art shows that there is a variety of VSM approaches, patents and software solutions. However, there is a lack of integration with regard to available VSM methodologies and IT solutions. To overcome supply chain barriers and incompatibilities, ongoing VSM standardization efforts within ISO/TC 154 are described comprising semantic as well as syntactic aspects in four main categories [Oberhausen, Minoufekr, Plapper, 2017-1]:

\section{1) VSM symbols}

Based on a set of standard symbols, which shall be used commonly, there is a clear and concise definition of VSM notation, especially for specific processes or use cases. This will avoid the use of similar, adapted or adjusted symbols and terminology, and thus prevent misunderstandings or deviations. 


\section{2) VSM data boxes and VSM parameters}

To achieve a uniform size and structure of VSM data boxes as well as a consistent use of parameters, common VSM data boxes and parameters that are suited for different process types are defined.

\section{3) Value stream calculation}

To quantitatively analyze value streams and to gain more detailed information about the performance of individual sections of the overall process chain, a consistent calculation procedure is envisaged.

\section{4) Value stream visualization}

In regard to the visualization of value stream data, there is a variety of available approaches. To achieve a common visualization of value streams, the value stream map (cf. Figure 2) is used within the standardization.

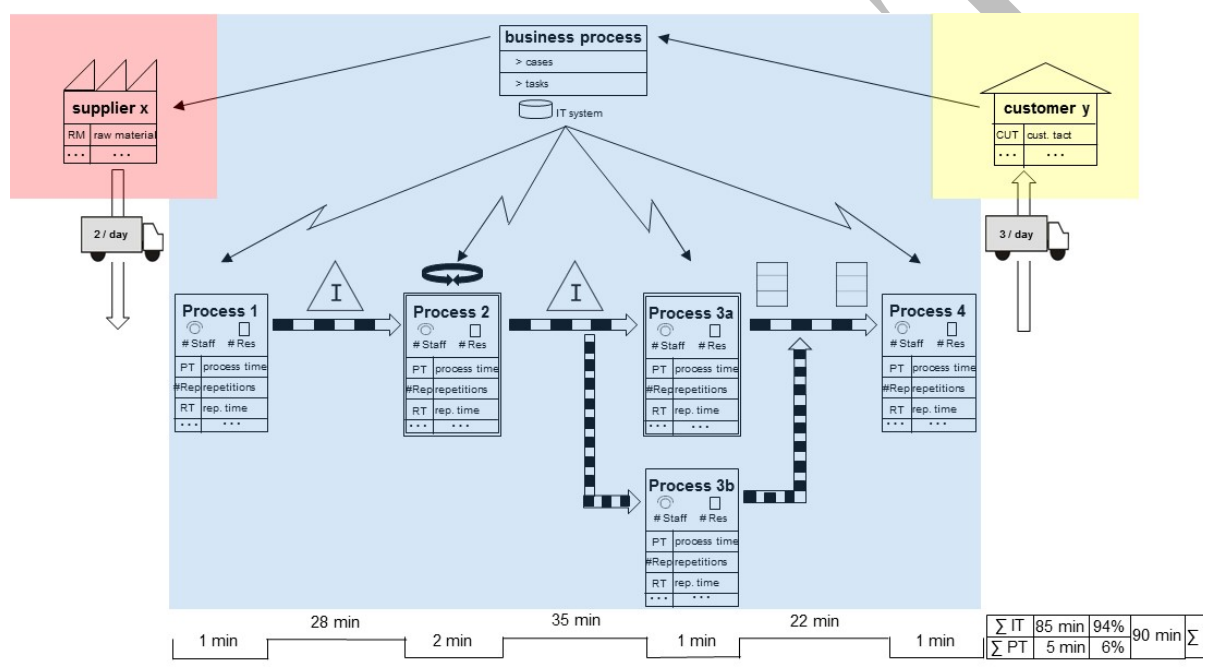

Figure 2: Value stream map as a typical visualization (quelle / Erstveröffentlichung angeben)

This diagram typically comprises the product and information flow from the supplier to the customer as well as a bottom line for a detailed analysis of the overall lead time. 


\section{MAIN FOCUS OF THE CHAPTER-HOW TO AUTHOR AN ISO STANDARD}

This part of the chapter is constructed as follow: First, a short introduction about ISO is given, before the different ISO-memberships are explained and the general proceeding to develop an ISO standard is explained in detail. The individual stages of the ISO standard are always exemplified by the development of ISO 22468.

\section{WHAT IS ISO?}

The International Organization for Standardization (ISO) is an independent, non-governmental international organization with a membership of 163 all over the world. It is a global network of national standards bodies with one member per country. The idea is to bring together experts who share their knowledge and develop on a voluntary basis, consensus-bases and marked relevant international standards that support innovation and provide solutions to global challenges [ISO 2019-4].

The initial aim of ISO was to 'facilitate the international coordination and unification of industrial standards', which came up in 1946 when delegates from 25 countries met at the Institute of Civil Engineers in London to create a new international organization. Around one year later, on 23 February 1947, ISO officially began its operations. Since that day, 22701 international standards that cover almost all aspects of technology and manufacturing have been published. [ISO 2019-4].

ISO ensures that products and services are safe, reliable and of good quality and provides a platform for the development. A standard is a document that contains practical information and best practices and often describes an agreed way of doing something or a solution for a global problem. Therefore, ISO standards help to make product compatible, identify safety issues of products and services and share good ideas, solutions, technical expertise and best management practices [ISO 2018].

By combining all of these statements, it is evident that ISO is associated with confidence and recognized globally [ISO 2018].

\section{ISO MEMBERSHIP}

ISO membership comes with rights, benefits, good practice and obligations. This means that every member need to actively take up his rights and benefits, follow good practice and adhere to his obligations, to deliver excellence within the ISO system [ISO 2015]

ISO is a global network of national standard bodies, where members are mainly standard organizations of their countries. Only one member per country exists and they represent ISO in their country. Based on the level of access and influence over the ISO system, three different member categories exist with up to four statutory member rights. The first right is to participate in developing ISO standards. The second right is to sell ISO standards and publications, and use copyright, the ISO name and logo. The third right is to participate in developing ISO policy and the fourth right is to participate in governing ISO [ISO 2015]. The first member category are full members or member bodies who participate and vote in ISO technical and policy meetings and thus influence the development and strategy of ISO standards. They have the right to sell and adopt ISO international standards nationally. The second member category are correspondent members who attend ISO technical and policy meetings as observer and thus monitor the development and 
strategy of ISO standards. They can sell and adopt ISO international standards nationally. The last member category are subscriber members who cannot participate actively in ISO's work but keep up to date. They do not have the right to sell or adopt ISO international standards nationally [ISO 2019-5]. Luxembourg is represented by ILNAS and is a full member.

Furthermore, ISO members can choose whether they want to be part of a particular technical committee (TC) and their level of involvement (O-member or P-member). O-members can observe the currently developed standards and offer comments and advice. They may vote, but don't have to. P-members have a voting obligation and need to actively participate by voting on standards at various stages of its development [ISO 2019-2].

Mostly, the experts who develop ISO standards work in the field and have expert knowledge. It is important that they understand and anticipate the challenges of their sector, and take advantage of standardizations to create a level playing field that benefits everyone. The participation of developing countries in standardization is supported through the Committee on Developing Country Matters (DEVCO). The knowledge and expertise of international standards can help developing countries realize their potential and by involving them in the development work, it is made sure that their needs are take into account [ISO 2019-2].

The main players in the ISO process are members, experts and ISO/Central Secretariat (CS). They are all connected and need to work together to develop new and consistent standards. Experts are writing the standards. ISO members approve standards, represent ISO in their country, enable national experts, propose new standards and help to manage technical committees. The ISO/CS strengthens relationships with partners, facilitates participation in standardization, provide a neutral platform, coordinates the standard development process and makes standards available and they increase awareness around international standards and ISO [ISO 2018].

\section{STAGES TO DEVELOP AN ISO STANDARD}

The following section describes the various stages of an ISO standard, from preliminary work to international publication

The ISO standard development is structured continuously and the stages follow a chronological numbering from 00 to 60 . Every stage is further divided into sub-stages. The structure is the following: The first substage is always the registration (00), the second one is the start of main action (20) and the third one is the completion of main action (60). Hereinafter, the decision (90) sub-stages are launched with as forth substage the repeat an earlier phase (92), as fifth the repeat current phase (93), as sixth the abandon (98) and as final sub-stage the proceed (99). Not every sub-stage is necessary within each stage, a summary of all the existing stages and sub-stages can be found in [ISO 2019-3]. A higher number signifies the increasing maturity of the new standard.

Before the different stages are explained individually, Table 1 gives an overview of the different stages with its associated documents, which need to be undergone during the development of an ISO norm.

\begin{tabular}{|l|l|}
\hline Project stage & Associated document \\
\hline Preliminary stage (00) & Preliminary work item (PWI) \\
\hline Proposal stage (10) & New work item proposal (NP) \\
\hline Preparatory stage (20) & Working draft(s) (WD) \\
\hline Committee stage (30) & Committee draft(s) (CD) \\
\hline Enquiry stage (40) & Enquiry draft (ISO/DIS) \\
\hline Approval stage (50) & Final draft international standard (FDIS) \\
\hline
\end{tabular}




\begin{tabular}{|l|l}
\hline Publication stage (60) & International standard (ISO)
\end{tabular}

Table 1: Project stages and associated documents [ISO/IEC 2019]

In the following, the stages to develop an ISO standard are explained in detail.

\section{Step 00 Preliminary stage}

Before starting with the elaboration of an ISO standard, it is common to conduct a preliminary stage (Step 00 ). This optional stage allows a workgroup to invest some preparatory work into the project like detecting the need of a new standard and the creation of a plan [ISO/IEC 2019].

\section{Step 10 Proposal stage (NWIP)}

The matter of the first step is to confirm that a new International Standard in the subject area is really needed [ISO 2019-6]. Any new standard needs to be introduced to the ISO expert teams as New Work Item Proposal (NWIP). Every NWIP needs to be submitted for vote using a specific form (form 4), which is available at the ISO website [ISO 2019-7]. Form 4 explains the justification of the future norm, contains a project plan and specifies the project leader. This information is assessed by the international experts, which are delegates of their country to the ISO Technical Committee (TC), and allow them to decide if they are going to participate on this topic or not.

For the voting, the electronic balloting portal shall be used and for a positive voting, two requirements need to be fulfilled. Firstly, the work item needs to be approved by a two-thirds majority of P-members of the technical committee. Secondly, at least 4 P-members (5 P-members in committees with 17 or more Pmembers) need to be nominated as technical experts and participate actively in the development of the project [ISO/IEC 2019]. They will represent the later Working Group (WG).

The authors of the future norm must be aware that at this point in time, they are forced to transfer copyright and ownership and commercial exploitation rights to ISO [ISO 2019-6].

For existing ISO standards, which have been published before, this NWIP phase can be skipped [ISO 2019$6]$.

In the case of VSM, the rationale was already explained in the previous parts of this chapter and even in more detail in [Oberhausen, 2018]. We were appointed to the technical committee 154 (Processes, data elements and documents in commerce, industry and administration), which deals with electronic data exchange. During the vote, the two-thirds majority was reached and technical experts from China, Germany, Republic of Korea, Luxembourg and Netherlands were nominated.

\section{Step 20 Preparatory stage (WD)}

During the preparatory stage, the preparation of a Working Draft (WD) is done by a working group which is set up by the parent committee. The WG is led by a convenor (usually the project leader) and composed of experts, which were nominated previously by the P-members. Together, they will author the future international standard [ISO 2019-6]. During this stage, it is important that the experts continue to look out for issues around copyright, patents and conformity assessment.

It exists two possibilities for the preparatory stage to end. Firstly, it can end when a working draft is available for circulation to the members of the technical committee or subcommittee as a first Committee Draft (CD). In this case, it is necessary to undergo stage 30 as well. Secondly, the committee can chose to skip stage 30 , the $\mathrm{CD}$. In this case, the preparatory stage ends when the enquiry draft (DIS) is available for circulation [ISO/IEC 2019].

Practical hints and a guideline how a new standard needs to be written can be downloaded here: [ISO 2016]. In the case of VSM, it was decided to undergo stage 30 as well. 


\section{Step 30 Committee stage (CD)}

Stage 30 is optional and can be skipped [ISO 2019-6]. However, if the committee stage is conducted, it can be seen as the principal stage, at which comments from National Bodies are taken into consideration. The Committee Draft (CD) shall be circulated to all P-members and O-members of the technical committee, to comment on the current work and receive further input. The goal is to reach consensus on the technical content and thus subsequent CDs can be circulated until consensus is reached on the technical content [ISO/IEC 2019].

To pass to the next stage, the leadership needs to decide whether the consenus has been reached or not. This includes if there is continual opposition or not. In case of doubt, it may be deemed to receive an approval by a two-thirds majority of P-members during a voting. As soon as the consensus has been reached within the technical committee, the responsible secretariat shall submit the finalized version of the draft in an electronic form. This will then be distributed to the national members for inquiry. The committee stage ends when all technical issues have been resolved and the committee draft is accepted for circulation as an enquiry draft [ISO/IEC 2019].

In the case of VSM, the committee draft was approved by a two-thirds majority of P-members vote, with additional comments from one P-member. These comments were incorporated before launching the next stage, the enquiry stage.

Step 40 Enquiry stage (DIS)

During the enquiry stage, the Draft International Standard (DIS) is circulated to all ISO members who have 12 weeks to vote and comment on the technical content [ISO 2019-6]. At this stage, it is of major importance, that positive votes (can be accompanied by editorial or technical comments) are only assigned if no unacceptable causes have been detected [ISO/IEC 2019].

The DIS is approved if two-third of the P-members of the TC are in favor and not more than one-quarter of the total votes (P-members and O-members) are negative [ISO 2019-6]. Depending on the results, three options are possible. Firstly, if the approval criteria are met and no technical changes are requested, the norm goes straight to publication stage. Secondly, if the quorum was reached but changes are required, the approval stage and a Final Draft International Standard (FDIS) will be used for resolving the issues. Thirdly, if the quorum was not reached, the enquiry draft will be revised and circulated for a subsequent voting [ISO/IEC 2019].

In the case of VSM, the DIS-ballot was started on the 26th of June 2019 and no results were available prior to the publication of this book.

\section{Step 50 Approval stage (FDIS)}

The approval stage is required only in case the approval criteria of the DIS-ballot were met but technical changes are required. So, if the draft requires technical changes following comments at the DIS stage, it is mandatory to undergo the approval stage and the Final Draft International Standard (FDIS). In this case, the FDIS is circulated to all ISO members for a voting, with the same approval criteria than for the DIS voting [ISO 2019-6].

The approval stage ends if the approval criteria have been met and the circulation of the voting report was done. This means, that two-third of the P-members of the TC are in favor and not more than one-quarter of the total votes are negative [ISO/IEC 2019].

In the case of VSM, this stage was at the being time not yet reached.

Stage 60: Publication stage 
After positive voting, only editorial corrections are provided to the final text of the standard, which is then published by the ISO Central Secretariat as an International Standard. The committee secretaries and project leaders get a two-week sign off period before the standard is published [ISO 2019-6].

\section{ADMINISTRATIVE USE CASE}

To prove that the proposed VSM method [Oberhausen, 2018] is suited as international norm, the suggested procedure needs to demonstrate its general applicability. It was already validated to analyze a versatility of value creation processes, like material-, energy- or data-related value steams [Oberhausen, Weber, Plapper, 2015], [Oberhausen \& Plapper, 2015], [Oberhausen \& Plapper, 2017], [Oberhausen, Minoufekr, Plapper, 2017-1], [Oberhausen, Minoufekr, Plapper, 2017-2], [Oberhausen, Minoufekr, Plapper, 2018].

Figure 3 summarizes the previously mentioned norming steps and exemplifies an administrative value stream. Each of these value adding steps requires approximately 6 months. The voting process takes approximately 3 months, during which the p-members reassure the vote with their national norming institutions. The voting period is administrative or idle time, during which no optimization of the text of the norm is performed.

Based on the "pull" principle, any lean value steam starts with the customer. In this specfic case, the general public (fig3, upper right corner), industrial partners and literature study indicated to the authors the pressing need for a common, globally applicable VSM standard. The development of the norm was based on existing knowledge, which was collected from patents, scientific publications, industrial companies and experts (upper left part). As preparatory work, the content of the new standard was developed, thoroughly validated in several use cases. With support of national norming authority, the first documentation was authored.

As the different stages of the norming process were undergone, the first two were performed with support of Luxembourgish ILNAS, and the following steps with support of ISO. Stage 30 and stage 50 may be skipped, depending on TC decision, which is illustrated by bypass flows. The standardization process will finish as soon as the standard is released to the general public (upper right part). Beneath, the timelines are shown (process-, idle- and lead time) with specific examples from ISO 22468.

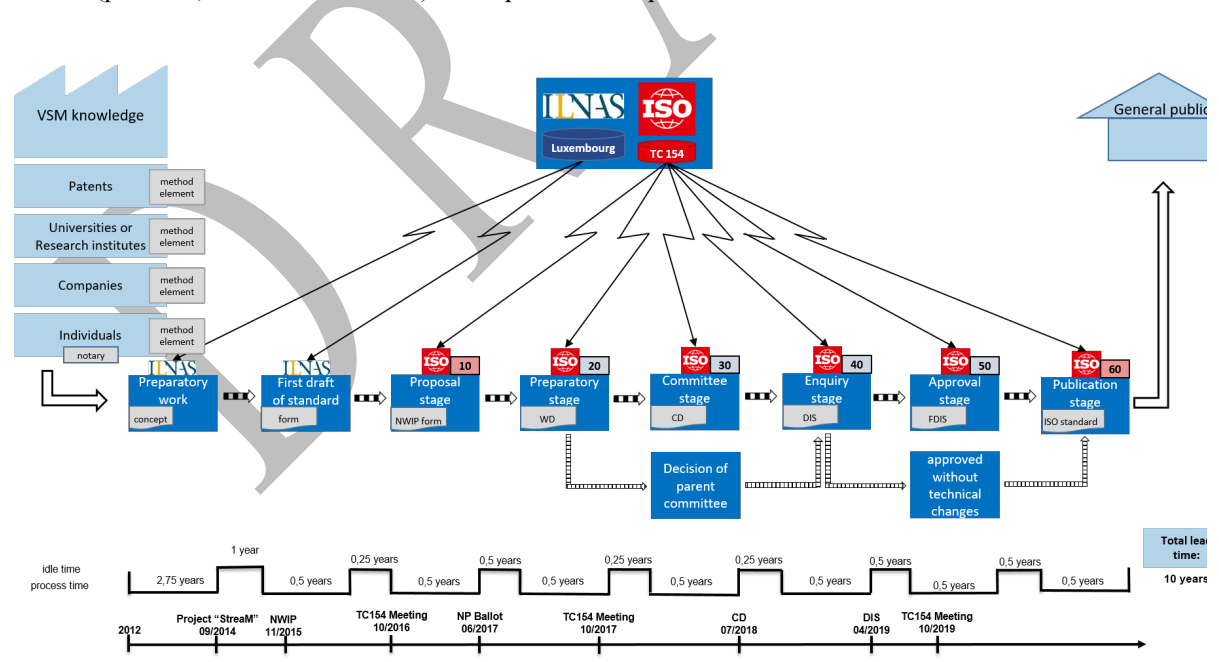

Figure 3: Value Stram Map of ISO standardization process 
ISO sponsors the development of the norm. The national norming institution, the« Institut Luxembourgeois de la Normalisation, de l'Accréditation, de la Sécurité et qualité des produits et services" (ILNAS) delegates the authors as experts to the Technical Committee154, where they serve as convener of Work Group 7 (ISO/ TC 154/WG 7), which hosts a.o. the development of the VSM norm.

The overall lead time is estimated to be approximately 10 years and it comprises value-adding times as well as non-value-adding times, whereby the latter are mainly the transition phases during which voting takes place. The ratio of value adding time to idle time results in a value adding share of $77,5 \%$. A more detailed analysis of the individual stages may lead to smaller value adding share.

The norm ISO 22468 meets all ISO requirements. In contrast to existing VSM methods, patents and software solutions, it provides a holistic VSM process, which is generally applicable to different industrial sectors. This common method enables to visualize, analyze and improve the value stream within companies and in SCN. It facilitates to reduce lead times, to diminish waste, and finally to reduce cost inside the company, at the interfaces of b-2-b partners and along the SCN. Concluding, the presented methodology will reduce misunderstands and hence improve the communication and collaboration within highly interconnected SCN.

\section{Issues, Controversies, Problems \\ SOLUTIONS AND RECOMMENDATIONS}

\section{FUTURE RESEARCH DIRECTIONS}

Future activities will mainly serve the continuation of the standardization activities as member of the ISO committees, leading to a comprehensive, universal VSM standard.

\section{CONCLUSION}

This chapter summarizes the different stages which are necessary to develop an ISO standard, from preliminary work to international publication. It shows the difficulties which need to be considered, the lengthiness of such a project and accuracy of an ISO standard. All in all, it proves why an ISO standard deserves such a prestigious reputation and is important for our daily life. The example of ISO 22468 underpins this statement and verifies the application of VSM through the administrative use case.

While operating in complex b-2-b networks, collaboration and communication issues arise for most global organizations. Originating from lean production, VSM is a powerful and at the same time easy-to-use tool, which is frequently used to analyze efficiency of product and information flows. However, prior state-ofthe-art showed a diversity of different VSM variants, patents and commercially available software. To provide the experts with a uniform understanding of value stream data, four different aspects of VSM were communized. ISO/ TC 154/ WG 7 hosts the development of the related VSM standard. This chapter describes the standardization process of ISO, which proves the applicability of the common method to visualize and analyze information-based, administrative value streams.

An international standard approved by ISO has significant implications and enables further efficiencies.

The VSM method, as defined in ISO 22468, is applicable to all process flows, which create value output. It enables to distinguish value adding tasks from non-value adding tasks (waste) and is a prerequisite to minimize the latter. 
The relevant value streams range from physical products, which are fabricated in manual operations one by one, to semi-automated manufacturing plants, up to fully automated, agile production systems. This method refers to low volume, serial production and to mass production value chains. In addition, this standard is also capable to analyze non-tangible processes or information-based value streams, like virtual, data-based processes, services and administrative processes. As example for the latter the VSM of the norming process is described here.

Using the VSM standard for further developments will provide experts with additional opportunities.

The ISO 22468 is validated for an individual station, for a complete plant, and even for a manufacturing network, composed of several companies, which form a supply chain network $(\mathrm{SCN})$.

Now, with the availability of an international common standard, the complete SCN, composed of many plants or several companies, who each create their individual share of value of the final product, can be analyzed and evaluated with this method to focus value creation to the end customer, rather than only the intermediate client.

\section{REFERENCES}

Brown, A., Amundson, J., \& Badurdeen, F. (2014). Sustainable value stream mapping (Sus-VSM) in different manufacturing system configurations: application case studies. Journal of Cleaner Production, 85, 164-179.

Erlach, K. (2013). Value Stream Design. Springer Berlin Heidelberg.

FlexSim Software Products Inc. (2017). FlexSimVSM. Retrieved January 26, 2017, from https://www.flexsim.com/value-stream-mapping/

Gao, R., Wang, L., Teti, R., Dornfeld, D., Kumara, S., Mori, M., \& Helu, M. (2015). Cloudenabled prognosis for manufacturing. CIRP Annals - Manufacturing Technology, 64(2), 749-772.

Hines, P., Rich, N., Bicheno, J., Brunt, D., Taylor, D., Butterworth, C., \& Sullivan, J. (1998). Value Stream Management. The International Journal of Logistics Management, 9(1), 25-42. 
ISO 2019-1. Benefits of ISO standards. Retrieved July 10, 2019, from https://www.iso.org/benefits-of-standards.html

ISO 2019-2. Who develops standards. Retrieved July 10, 2019, from https://www.iso.org/whodevelops-standards.html

ISO 2019-3. All about ISO - Members. Retrieved July 10, 2019, from https://www.iso.org/stagecodes.html

ISO 2019-4. All about ISO. Retrieved July 10, 2019, from https://www.iso.org/about-us.html https://www.iso.org/about-us.html

ISO 2019-5. International harmonized stage codes. Retrieved July 10, 2019, from https://www.iso.org/members.html

ISO 2019-6. Developing ISO standards. Retrieved July 10, 2019, from https://www.iso.org/stagesand-resources-for-standards-development.html

ISO 2019-7. ISO forms, model agendas, standard letters. Retrieved July 10, 2019, from https://www.iso.org/iso-forms-model-agendas-standard-letters.html

ISO/IEC 2015. ISO membership manual. Downloaded on July 10, 2019 from https://www.iso.org/files/live/sites/isoorg/files/archive/pdf/en/iso_membership_manual.pdf

ISO 2016. How to write standards. Downloaded on July 10, 2019 from https://www.iso.org/files/live/sites/isoorg/files/archive/pdf/en/how-to-write-standards.pdf

ISO 2018. ISO in brief - Great things happen when the world agrees. Downloaded on July 10, 2019 from https://www.iso.org/files/live/sites/isoorg/files/store/en/PUB100007.pdf

ISO/IEC 2019. Directives, Part 1 Consolidated ISO Supplement - Procedures specific to ISO. $\begin{array}{lllll}\text { downloaded } & \text { on } & \text { July } & 10, & \text { from }\end{array}$ https://www.iso.org/sites/directives/current/consolidated/index.xhtml

Keyte, B., \& Locher, D. A. (2004). The Complete Lean Enterprise: Value Stream Mapping for Administrative and Office Processes. CRC Press.

Klevers, T. (2007). Wertstrom-Mapping und Wertstrom-Design. mi-Fachverlag.

LEANPILOT GmbH. (2017). LEANPILOT. Retrieved January 26, 2017, from http://www.leanpilot.com/index.html

Oberhausen, C., \& Plapper, P. (2015). Value Stream Management in the "Lean Manufacturing Laboratory." In CIRP Conference on Learning Factories, Bochum, 2015. 
Oberhausen, C., Weber, D., and Plapper, P. (2015). Value Stream Management in high variability production systems. SSRG Int. J. Ind. Eng., vol. 2, no. 1, pp. 1-4.

Oberhausen, C., \& Plapper, P. (2016). A Standardized Value Stream Management Method for Supply Chain Networks. In D. Dimitrov \& T. Oosthuizen (Eds.), Proceedings of COMA'16 International Conference on Competitive Manufacturing (pp. 428-433). COMA'16 in Stellenbosch, South Africa.

Oberhausen, C., \& Plapper, P. (2017). Cross-Enterprise Value Stream Assessment. Journal of Advances in Management Research, 14(2), 182-193.

Oberhausen, C., Minoufekr, M., Plapper, P. (2017-1). Standardized Value Stream Management Method to Visualize, Analyze and Optimize Cross-Enterprise Value Stream Data. International Journal of Standardization Research, vol. 15

Oberhausen, C., Minoufekr, M., Plapper, P. (2017-2). Continuous Improvement of Complex Process Flows by Means of Stream as the "Standardized Cross-Enterprise Value Stream Management Method". IEEE IEEM

Oberhausen, C., Minoufekr, M., Plapper, P. (2018). Application of Value Stream Management to enhance Product and Information Flows in Supply Chain Networks - Based on the example of Web-Based Automotive Retail Business. Management and Production Engineering Review, vol. 9

Oberhausen, C. (2018). Standardisierte Unternehmensübergreifende Wertstrommethode (StreaM). Dissertation, Université du Luxembourg

Plapper, P., \& André, C. (2011). Wertstrommethode - Value Stream Mapping. In Der Qualitätsmanagement-Berater (10th ed., pp. 1-27).

Profit Surge Consulting. (2017). Profit Surge VSM Software. Retrieved January 26, 2017, from http://profit-surge.com/ProfitSurgeVSM.html

Rother, M., \& Shook, J. (1999). Learning to see: value-stream mapping to create value and eliminate muda (1.2). Lean Enterprise Institute.

Schäfermeyer, M., \& Rosenkranz, C. (2011). To Standardize or not to Standardize? Understanding the Effect of Business Process Complexity on Business Process Standardization. ECIS 2011 Proceedings.

Schmitz, V., \& Leukel, J. (2005). Findings and Recommendations from a Pan-European Research Project: Comparative Analysis of E-Catalog Standards. International Journal of IT Standards and Standardization Research, 3(2), 51-65. 
Siemens PLM Software Inc. (2017). Tecnomatix. Retrieved January 26, 2017, from https://www.plm.automation.siemens.com/en_us/products/tecnomatix/manufacturingsimulation/material-flow/plant-simulation.shtml

Sources of pictures in Figure 1: "Radial Tyre Steel Cord for Truck Tire"; "Goodyear Assurance ComforTred Touring"; "Opel Insignia Sedan". Retrieved January 26, 2017, from http://entron.en.made-in-china.com; https://www.goodyear.com; https://www.carlook.net.

The eVSM Group. (2017). eVSM. Retrieved January 26, 2017, from https://evsm.com/

Wang, W. Y. C., Heng, M. S. H., \& Chau, P. Y. K. (2007). Supply Chain Management: Issues in the New Era of Collaboration and Competition. Retrieved from http://www.loc.gov/catdir/toc/ecip0611/2006010099.html

Womack, J. P., \& Jones, D. T. (2011). Seeing the Whole Value Stream, 2nd Ed.: Lean Enterprise Institute.

\section{ADDITIONAL READING}

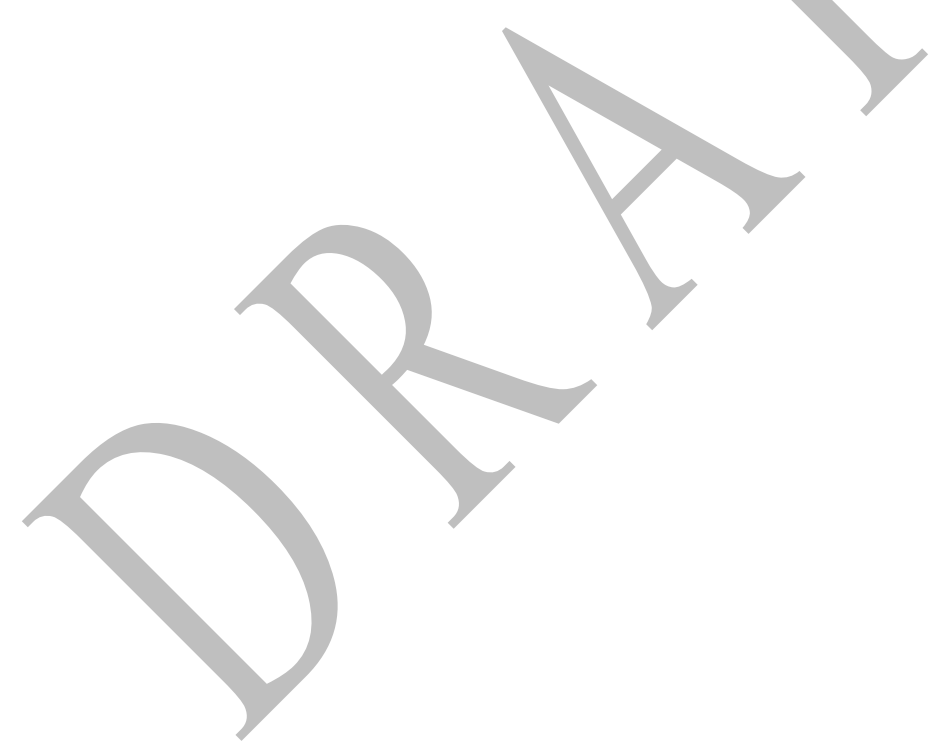


KEY TERMS AND DEFINITIONS

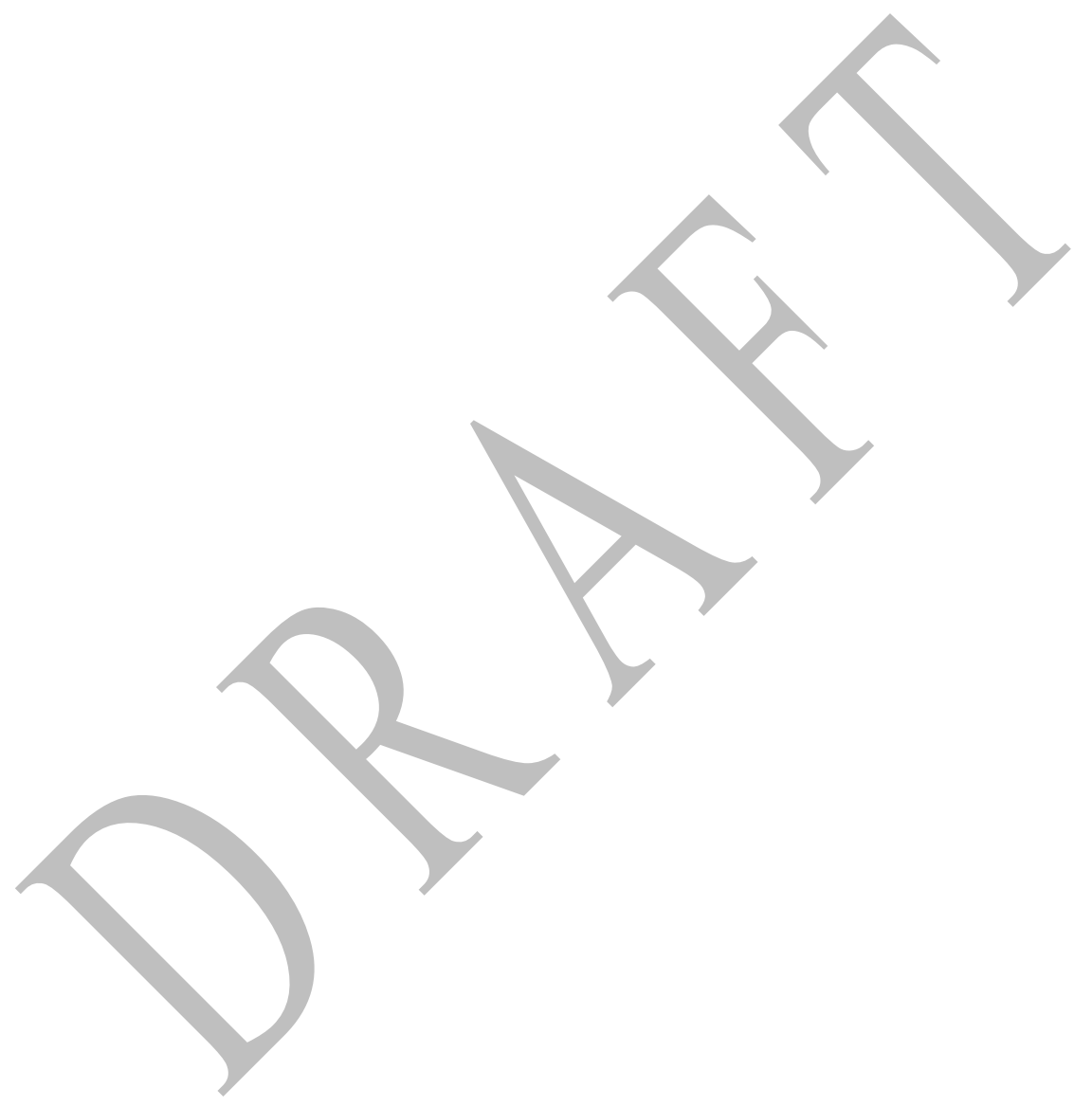


APPENDIX 1

\begin{tabular}{|c|c|c|c|}
\hline No. & Patent & Applicant & $\begin{array}{l}\text { Country/ } \\
\text { Region }\end{array}$ \\
\hline WO2014138271 & $\begin{array}{l}\text { Cloud-based real-time value stream } \\
\text { mapping system and method }\end{array}$ & Whitehead, C. & World \\
\hline US 20060242005 A1 & $\begin{array}{l}\text { Comprehensive method to improve } \\
\text { manufacturing }\end{array}$ & $\begin{array}{l}\text { Rodrigue, R.P. } \\
\text { et al. }\end{array}$ & USA \\
\hline US $20070005451 \mathrm{~A} 1$ & Crop Value Chain Optimization & Iwig, R.C. et al. & USA \\
\hline WO 2008021400 A2 & $\begin{array}{l}\text { Dynamic Value Stream Mapping } \\
\text { Software }\end{array}$ & Glenn, J.R. et al. & World \\
\hline US 20100070425 A1 & $\begin{array}{l}\text { Ecosystem value stream optimization } \\
\text { system, method and device }\end{array}$ & & USA \\
\hline US 20140365266 A1 & Enterprise Process Evaluation & & USA \\
\hline US 7383192 B2 & $\begin{array}{l}\text { Method for displaying Product Value } \\
\text { Chain Flow Diagram and Product } \\
\text { Value Chain Data }\end{array}$ & Sekimoto, S. et al. & \\
\hline US20080077445A1 & $\begin{array}{l}\text { Method of Healthcare Delivery With } \\
\text { Value Stream Mapping }\end{array}$ & Mecklenburg, R. & USA \\
\hline US20060080157 A1 & $\begin{array}{l}\text { Method of improving administrative } \\
\text { functions of a business using value } \\
\text { streams with display of status }\end{array}$ & Shuker, T. & USA \\
\hline US 20060085237 A1 & $\begin{array}{l}\text { Method of improving information } \\
\text { technology processes of a business } \\
\text { using Value Stream Management }\end{array}$ & $\begin{array}{l}\text { Shuker, T. \& } \\
\text { Luckman, J. }\end{array}$ & USA \\
\hline WO 2007067892 A2 & $\begin{array}{l}\text { System and method for dynamically } \\
\text { simulating value stream and network } \\
\text { maps }\end{array}$ & Adra, H.I. & World \\
\hline WO2011075444A1 & $\begin{array}{l}\text { System and method for Process } \\
\text { Improvement and associated products } \\
\text { and services }\end{array}$ & Ansley, R. & World \\
\hline $\begin{array}{l}\text { EP1139251A2, } \\
\text { EP1139251A3, } \\
\text { US7280973B1, } \\
\text { CA2404081A1 }\end{array}$ & $\begin{array}{l}\text { Value Chain Optimization System } \\
\text { and Method }\end{array}$ & Hack, S. et al. & $\begin{array}{l}\text { Europe, } \\
\text { USA, } \\
\text { Canada }\end{array}$ \\
\hline US $20050154575 \mathrm{~A} 1$ & $\begin{array}{l}\text { Value stream improvement process } \\
\text { simulation }\end{array}$ & $\begin{array}{l}\text { Whitman, J.M. \& } \\
\text { Treiber, K.K.R. }\end{array}$ & USA \\
\hline US 20040039625 A1 & $\begin{array}{l}\text { Value stream process management } \\
\text { approach and web-site }\end{array}$ & Malnack, S.J. et al. & USA \\
\hline US20090031598 A1 & $\begin{array}{l}\text { Value Stream Simulation and Display } \\
\text { Board }\end{array}$ & $\begin{array}{l}\text { Soni, A. \& } \\
\text { Malnati, P.A. }\end{array}$ & USA \\
\hline
\end{tabular}

ENDNOTES / ACKNOWLEDGMENT (Optional)

The authors are grateful to the following supporters of this research:

- Interreg NWE, project Di-Plast - Digital Circular Economy for the Plastics Industry

- "Institut Luxembourgeois de la Normalisation, de l'Accréditation, de la Sécurité et qualité des produits et services" (ILNAS) for coaching us as convener of WG 7 in ISO/TC 154

- Euro-Composites S.A. for ongoing support of the development of the norm with industrial requirements - Fonds National de la Recherche (FNR) Luxembourg, for financing of a previous, preparatory research project 


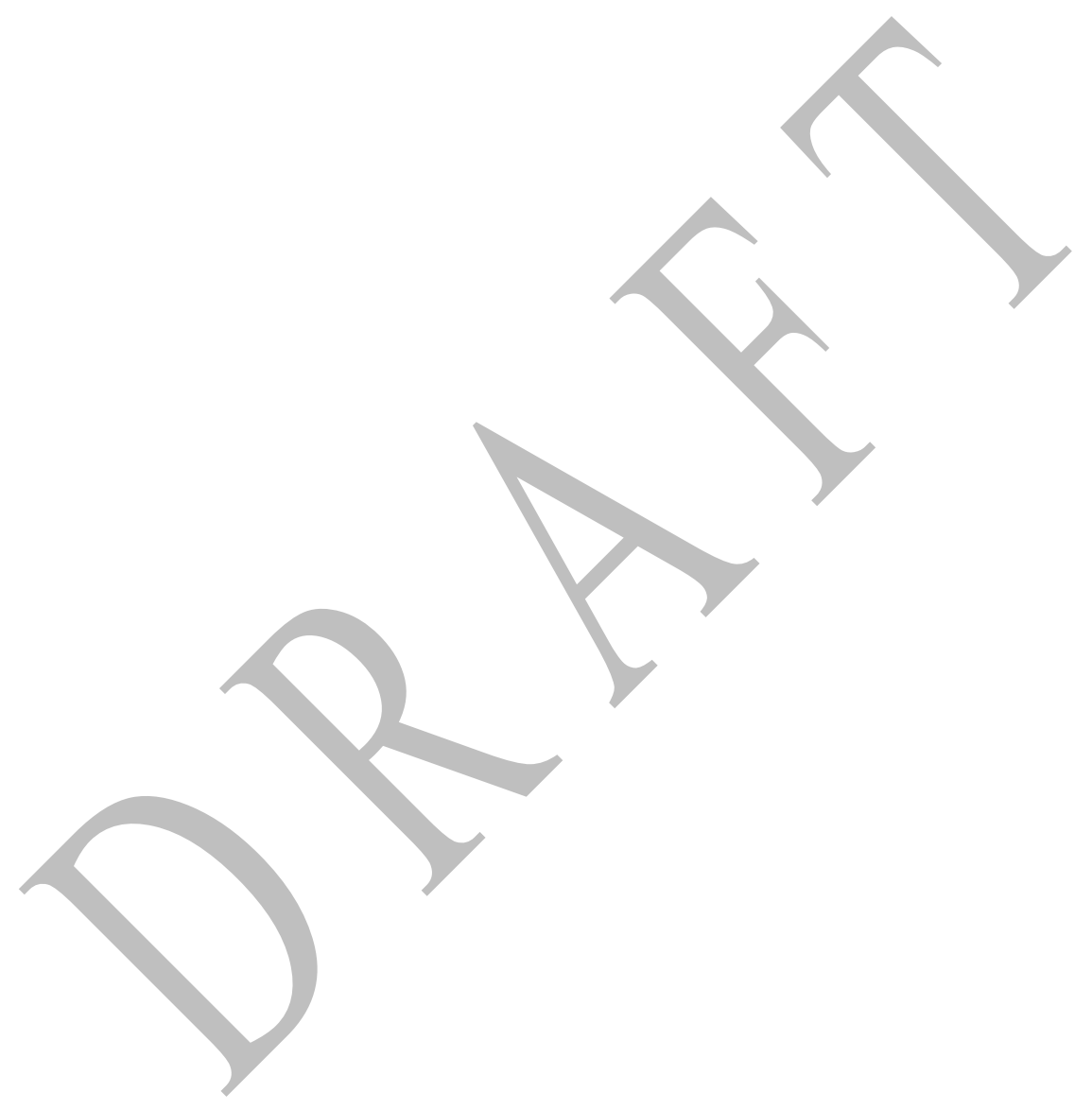

